\title{
Editorial for the Special Issue
}

\author{
Takeshi HATTA (Guest Editor)
}

Nagoya University, Japan

This special issue is based upon the joint-project between Nagoya University (School of Informatics and Sciences) and the NTT Communication Science Laboratory from 1998 to 2000. In early 1997, Dr. K. Matsuda, at that time he was the director of the NTT Communication Science Laboratory, invited me to his Kyoto office and he introduced his new idea to develop his laboratory. According to Dr. Matsuda, his institute has made steady progress in research field, however the activities were basically based upon the communication technology. He stressed the importance of social and human factor in future communication science research. I agreed with his idea and promised support to his project as an old friend since teen age. Then, we started a new research group, computer mediated communication (CMC) in 1997.

The distribution of cheap personal computer since around 1990 brought the dramatic increase of computer mediated communication. For example, the number of Internet users in Japan has increased dramatically since 1997 (White Paper from Ministry of Public Managements, Home Affairs, Post and Telecommunications, 2002). Internet usage in Japan was reaching an estimated 47.08 million at the end of 2000 (it is up $74 \%$ of the previous year). About 37 million Internet users access the Internet via PC, while 24 million gain access via mobile phones. The number of Internet service providers in Japan has grown along with the number of users, reaching 5,612 operators at the end of March 2001. This kind of changes of social circumstances has occurred not only in Japan but also in many countries.

Needless to say, the change of social circumstances necessarily invites the change of human behavior in various facets. People began to buy various materials by Internet auction and e-shop. People became not to take note the scheduled time and place but started to consult mobile phone to call up him/her at the set time. People started to look for anonymous friend by Internet to enjoy meaningless chat and occasionally even committed a suicide together with those unknown friends.

As seen from these examples, the introduction of $\mathrm{CMC}$ has changed social circumstances and human behavior patterns drastically. As pointed out by Dr. K. Matsuda, we are now facing at the changing phase of social circumstances and human behavior by the distribution of personal computer and mobile phone. However, systematic scientific approaches from the social and psychological background to examine the effects of the introduction of CMC have not been conducted fully, compared to the contribution from technological research backgrounds. As mentioned earlier, Dr.

Correspondence: Takeshi Hatta, Graduate School of Environmental Studies, Nagoya University, Chikusaku, Nagoya City, 464-8601, Japan (e-mail: thatta@info.human.nagoya-u.ac.jp). 
K. Matsuda proposed to conduct a joint study with his laboratory and Nagoya research group and we decided to address a new research field, which aims to examine the relation between human behavior and CMC.

Therefore, firstly, I have to appreciate Dr. K. Matsuda for his support to our CMC research group and pay my respect to his intention to cultivate new research horizon. With the help of next director, Dr. Y. Tohkura, and Professor T. Muto (Ochanomizu University), Professor Y. Kawaura (Yokohama City University), and other members, we started the activity. The CMC (later CMCC: Computer mediated communication and community) took place open symposium at Nara, Osaka, and Tokyo, from 1998 to 2000 two times per year. Various topics which relate to the computer, communication, and human behavior such as characteristics of e-mail communication, communication style by mobile phone, ways to use computer as an aid of external memory, ways to construct new knowledge with collaboration by human and computer, relations between memory delay in human and computer memory, etc.

As the limitation of time for Open Symposium, only small parts of research were presented and we searched the chance to publish research findings which have done by young researchers. When I asked the opportunity to publish CMC studies to the previous editor in chief of Psychologia, Professor M. Koyasu, he kindly agreed with and offer the chance. Therefore, I called submission for young researchers to the special issue of Psychologia. I asked professor J. Kawaguchi (Nagoya University), Professor K. Karasawa (Nagoya University) and Dr. Jim O. Robinson (Cardiff University) to join the reviewing of the submitted articles.

In this special issue, we aimed to collect studies, which related human behavior and CMC by young cognitive and social psychologists and also invited two researchers from USA and UK to contribute this special issue. It is our aim to inform the readers that the Psychologia welcomes new research articles, which examine the effect and influence of $\mathrm{CMC}$ on human behavior and social circumstances.

I have to thank many people for their contribution to the activity of CMC. Their names were Drs. T. Yamaki, T. Iida, K. Matsuzawa, T. Yukawa, T. Makino, M. Ohta, T. Kato, K. Ishii, S. Katagiri (NTT Communication Science Laboratory), T. Kogure (Fukushima University), and H. Watanabe (Tokyo University).

Finally, I appreciate very much to Professor M. Koyasu, Professor S. Yoshikawa, and Ms. T. Kuroda for their patience to edit this special issue.

It is our pleasure if this special issue somehow stimulates scientific mind of young psychologists and sociologists and encourage their trials, which relate to cultivate a new research horizon. 